\title{
The Histone Lysine-specific Demethylase 1 Inhibitor, SP2509 Exerts Cytotoxic Effects against Renal Cancer Cells through Downregulation of $\mathrm{Bcl}-2$ and $\mathrm{Mcl}-1$
}

\author{
Kaixin Wu, Seon Min Woo, Taeg Kyu Kwon \\ Department of Immunology, School of Medicine, Keimyung University, Daegu, Korea
}

\begin{abstract}
Lysine-specific histone demethylase 1 (LSD1), also known as KDM1A, can remove the methyl group from lysine 4 and 9 at histone $\mathrm{H} 3$, which regulates transcriptional suppression and activation. Recently, high expression of LSD1 in tumors has been shown to be involved in cancer cell proliferation, metastasis, and poor prognosis. We found that SP2509, a potent and reversible inhibitor of LSD1, induced apoptosis in human renal carcinoma (Caki and ACHN) and glioma (U87MG) cells. Pharmacological inhibition and siRNA-mediated silencing of LSD1 expression effectively downregulated anti-apoptotic proteins such as Bcl-2 and Mcl-1. Ectopic expression of these proteins markedly attenuated SP2509-induced apoptosis. At a mechanistic level, we found that inhibition of LSD1 downregulated Bcl-2 at a transcriptional level. Interestingly, protein expression of Mcl-1 was modulated at a post-translation level. Our results reveal that LSD1 could induce apoptotic cell death in renal carcinoma cells through downregulation of Bcl-2 and Mcl-1.
\end{abstract}

Key Words KDM1A, SP2509, Bcl-2, Mcl-1, Apoptosis

\section{INTRODUCTION}

Histone methylation has been known as a key event for transcriptional regulation of genes, and many researchers have considered that histone methylation is an irreversible epigenetic marker [1]. However, Shi et al. [2] have reported that histone methylation is a reversible process through the discovery of the nuclear amine oxidase homolog LSD1 with histone demethylating activity. Histone demethylases are classified into 2 classes depending on the catalytic mechanisms; the flavin adenine dinucleotide-dependent amine oxidases (LSD1 and LSD2) and Jumonji domain containing proteins [3,4]. Specially, LSD1 binds to the promoter regions, demethylases lysine 4 and 9 at histone H3 (H3K4me1/2 and H3K9me1/2), and acts as a repressor or an activator of transcription. Demethylation of $\mathrm{H} 3 \mathrm{~K} 4 \mathrm{me} 1 / 2$ or $\mathrm{H} 3 \mathrm{~K} 9 \mathrm{me} 1 / 2$ by LSD1 induces gene transcription suppression or activation via inhibition of mono- and dimethyl group(s), respectively [5,6].

Pathologically, expression of LSD1 is elevated in many cancer cells including neuroblastoma [7], leukemia [8], lung [9], colon [10], and breast cancer [11], which is associated with cancer cell proliferation, metastasis and poor prognosis $[12,13]$. Therefore, dysregulation of LSD1 can potentiate cancer treatment through inhibition of cancer cell proliferation and metastasis. Kumar et al. [14] have reported that LSD1/2 is highly expressed in renal cell carcinoma with clinical correlation as prognostic markers. Recently, multiple reversible LSD1 inhibitors have been developed. Among them, SP2509 is a non-competitive and potent inhibitor of LSD1 with anti-proliferative and anti-cancerous activities [15]. SP2509 inhibits proliferation through induction of ER stress response, as well as induces apoptosis in Ewing sarcoma cells $[16,17]$. Co-treatment with SP2509 and panobinostat (pan-HDAC inhibitor) was synergistically cytotoxic against acute myeloid leukemia [16]. Although the anti-cancer effects of SP2509 have been reported in several cancer cells, its molecular mechanism is still not clear.

In this study, we have found that SP2509 induces apoptosis by downregulation of $\mathrm{Bcl}-2$ and $\mathrm{Mcl}-1$ in human renal cancer cells. 


\section{MATERIALS AND METHODS}

\section{Cell cultures and materials}

Human renal carcinoma cells (Caki and ACHN), human glioma carcinoma cells (U87MG), and human normal TCMK-1 cells were obtained from the American Type Culture Collection (ATCC, Manassas, VA, USA). Human renal mesangial cells were purchased from Lonza (Basel, Switzerland). All cells were cultured in appropriate medium containing $10 \%$ FBS (Welgene, Gyeongsan, Korea), 1\% penicillin-streptomycin and $100 \mu \mathrm{g} / \mathrm{mL}$ gentamycin (Thermo Fisher Scientific, Waltham, MA, USA). R\&D System (Minneapolis, MN, USA) supplied the recombinant ZVAD-fmk. MG132 and lactacystin were purchased from Calbiochem (San Diego, CA, USA) and Biomol Research Laboratories (Plymouth Meeting, PA, USA), respectively. Cycloheximide (CHX) and $\beta$-actin (A5441) were purchased from Sigma-Aldrich (St. Louis, MO, USA). The PCR primers were purchased from Macrogen (Seoul, Korea). Anti-PARP (\#9542S), anti-DR5 (\#2764S), anti-cleaved caspase-3 (\#9661S), and anti-Bcl-xL (\#2764S) antibodies were supplied by Cell Signaling Technology (Beverly, MA, USA). Anti-C-FLIP (ALX-804-961-0100) and ani-USP9X (H00008239-M01) antibodies were obtained from Enzo Life Sciences (San Diego, CA, USA) and Abnova (Taipei City, Taiwan), respectively. Anti-Bim (AB17003), anti-Bax (554104), anti-caspase-3 (610322), and anti-XIAP (610762) antibodies were products of BD Biosciences (San Jose, CA, USA). Anti-clAP2 (SC-7944), anti-Mcl-1 (SC-12756), anti-Bcl-2 (SC783), anti-LSD1 (SC-271720), and anti- $\beta$-TrCP (SC-33123) antibodies were provided from Santa Cruz Biotechnology (Santa Cruz, CA, USA).

\section{Flow cytometry analysis and Western blotting}

For apoptosis analysis, cells were fixed with $100 \%$ ethanol for 2 hours at $4^{\circ} \mathrm{C}$, resuspended in $250 \mu \mathrm{L}$ of $1.12 \%$ sodium citrate buffer ( $\mathrm{pH} 8.4)$ containing RNase $(12.5 \mu \mathrm{g} / \mathrm{mL})$, and incubated for 30 minutes at $37^{\circ} \mathrm{C}$. After that, cellular DNA was stained with $250 \mu \mathrm{L}$ of propidium iodide $(50 \mu \mathrm{g} / \mathrm{mL})$. The stained cells were analyzed by flow cytometer (BD Biosciences). To examine protein expression, cells were lysed in RIPA lysis buffer and centrifuged at $12,000 \times g$ at $4^{\circ} \mathrm{C}$ for 15 minutes. The proteins were separated by SDS-PAGE electrophoresis and transferred to an Immobilon-P membrane (GE Healthcare Life Science, Pittsburgh, PO, USA). The specific membranes were detected using an Immobilon Western Chemiluminescent HRP Substrate (EMD Millipore, Darmstadt, Germany).

\section{DNA fragmentation and 4', 6'-diamidino-2- phenylindole (DAPI) staining}

To detect apoptosis, DNA fragmentation was performed using the Cell Death Detection ELISA ${ }^{\text {PLUS }}$ kit (Boehringer Mannheim, Indianapolis, IN, USA). For DAPI staining, the cells were fixed with $1 \%$ paraformaldehyde, washed with PBS, and stained with $300 \mathrm{nM}$ DAPI solution (Roche, Mannheim, Germany) for 5 minutes. The nucleus condensation was tested by fluorescence microscopy (Carl Zeiss, Jena, Germany).

\section{DEVDase activity assay}

Caki cells were treated with the indicated concentrations of SP2509 for 24 hours, harvested and incubated with reaction buffer containing substrate (acetyl-Asp-Glu-Val-Asp p-nitroanilide.

\section{Reverse transcription-PCR and quantitative real-time PCR (qPCR)}

Total cellular RNA was exacted using the Trizo $^{\circledR}$ reagent (Life Technologies, Gaithersburg, MD, USA). cDNA was obtained using M-MLV reverse transcriptase (Gibco-BRL, Gaithersburg, MD, USA) [17]. The following primers were used for the amplification of human Bcl-2, Mcl-1, and actin: Bcl-2 (forward) 5'-GGT GAA CTG GGG GAG GAT TGT-3' and (reverse) 5'CTT CAG AGA CAG CCA GGA GAA-3'; Mcl-1 (forward) 5'GCG ACT GGC AAA GCT TGG CCT CAA-3' and (reverse) TT ACA GCT TGG ATC CCA ACT GC-3'; and actin (forward) 5'-GGC ATC GTC ACC AAC TGG GAC-3' and (reverse) 5'CGA TTT CCC GCT CGG CCG TGG-3'. For PCR, we used Blend Taq DNA polymerase (Toyobo, Osaka, Japan) with primers targeting Bcl-2, Mcl-1 and actin: Bcl-2 (forward) 5'GGT GAA CTG GGG GAG GAT TGT-3' and (reverse) 5'-CTT CAG AGA CAG CCA GGA GAA-3'; Mcl-1 (forward) 5'-ATG CTT CGG AAA CTG GAC AT-3' and (reverse) 5'-TCC TGA TGC CAC CTT CTA GG-3'; and actin (forward) 5'-CTA CAA TGA GCT GCG TGT G-3' and (reverse) 5'-TGG GGT GTT GAA GGT CTC-3'. The amplified products were separated by electrophoresis on a $2 \%$ agarose gel and detected under ultraviolet light. For qPCR, SYBR Fast qPCR Mix (Takara Bio Inc., Shiga, Japan) was used, and reactions were performed on Thermal Cycler Dice ${ }^{\circledR}$ Real Time System III (Takara Bio Inc.) [18].

\section{Transfection}

For knockdown of LSD1 using siRNA (Santa Cruz Biotechnology), cells were transfected using Lipofectamine ${ }^{\circledR}$ RNAiMAX Reagent (Invitrogen, Calshad, CA, USA). For constructing stable cell lines, Caki cells were transfected in a stable manner using Lipofectamine ${ }^{\mathrm{TM}} 2000$ (Invitrogen) with the pcDNA3.1(+)/Bcl-2 and pcDNA(3.1+)/Mcl-1. After incubation for 48 hours, cells were replaced with fresh medium and selected by the G418 $(700 \mu \mathrm{g} / \mathrm{mL})$. To measure luciferase activity, Bcl-2/-751 and Bcl-2/-1281 promoter-constructs were transfected into the Caki cells using Lipofectamine ${ }^{\mathrm{TM}} 2000$ (Invitrogen). After transfection, cells were treated with $2 \mu \mathrm{M}$ SP2509 for 24 hours, and lysates were incubated with luciferase substrates. Aliquots of the supernatant were used for the luciferase assay according to the manufacturer's instructions (Promega, Madison, WI, USA). 


\section{Statistical analysis}

The data were analyzed using a one-way ANOVA and posthoc comparisons (Student-Newman-Keuls) using the Statistical Package for Social Sciences ver. 22.0 software (IBM Corp., Armonk, NY, USA).

\section{RESULTS}

\section{The LSD1 inhibitor SP2509 induces apoptosis} in human renal Caki cells

LSD1 is highly expressed in multiple cancer cells. We investigated whether the LSD1 inhibitor, SP2509 could induce apoptosis in renal carcinoma Caki cells. SP2509 induced apoptosis-related morphological changes, such as nuclear chromatin condensation, and dose-dependently increased sub-G1 population, PARP cleavage and cytoplasmic histone-associated DNA fragments (Fig. 1A-1C). We investigated the involvement of caspases in SP2509-induced apoptosis. SP2509 increased caspase-3 (DEVDase) activity in a dose-dependent manner (Fig. 1D). Moreover, a pan-caspase inhibitor z-VAD blocked SP2509-induced increases in sub-G1 population and PARP cleavage (Fig. 1E). Therefore, these results indicate that the LSD1 inhibitor SP2509 induces caspase-dependent cancer cell death.

\section{Inhibition of LSD1 decreases expression levels of anti-apoptotic $\mathrm{Bcl}-2$ family proteins}

To investigate the molecular mechanism responsible for SP2509-induced apoptosis, we analyzed the expression levels of apoptosis-related proteins. SP2509 induced downregulation of $\mathrm{Bcl}-2$ and $\mathrm{Mcl}-1$, whereas other proteins did not change (Fig. 2A). Next, we checked mRNA levels of Bcl-2 and $\mathrm{Mcl}-1$ in SP2509 treated cells. As shown in Figure 2B, SP2509 inhibited Bcl-2 mRNA expression, whereas the Mcl-1 mRNA level did not change (Fig. 2B).

To further investigate whether inhibition of LSD1 is associated with modulation of $\mathrm{Bcl}-2$ and $\mathrm{Mcl}-1$ expression, we used LSD1 siRNA. Knockdown of LSD1 decreased Bcl-2 and Mcl-
A

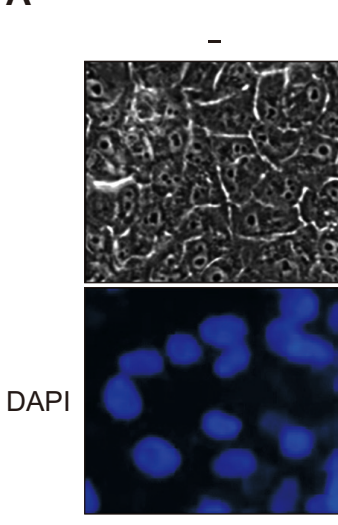

C

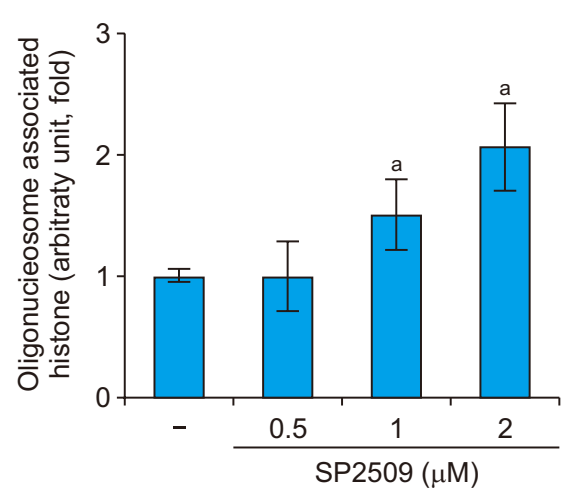

$\operatorname{SP} 2509(\mu \mathrm{M})$

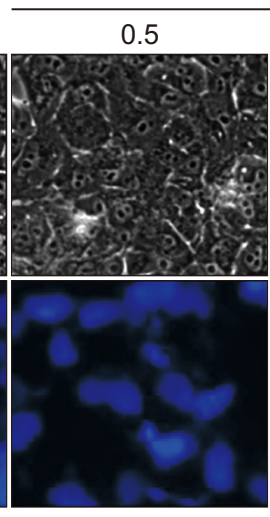

D

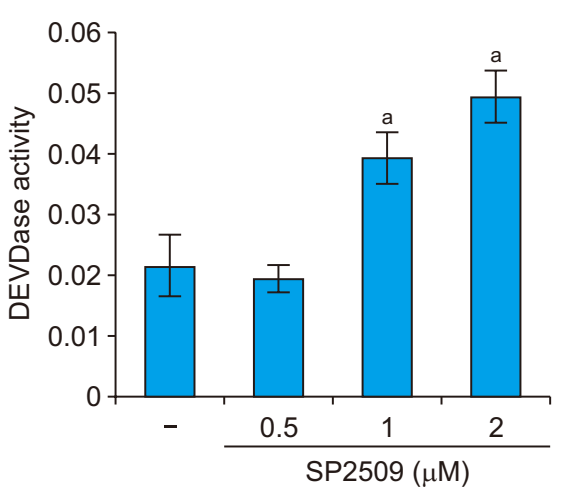

B
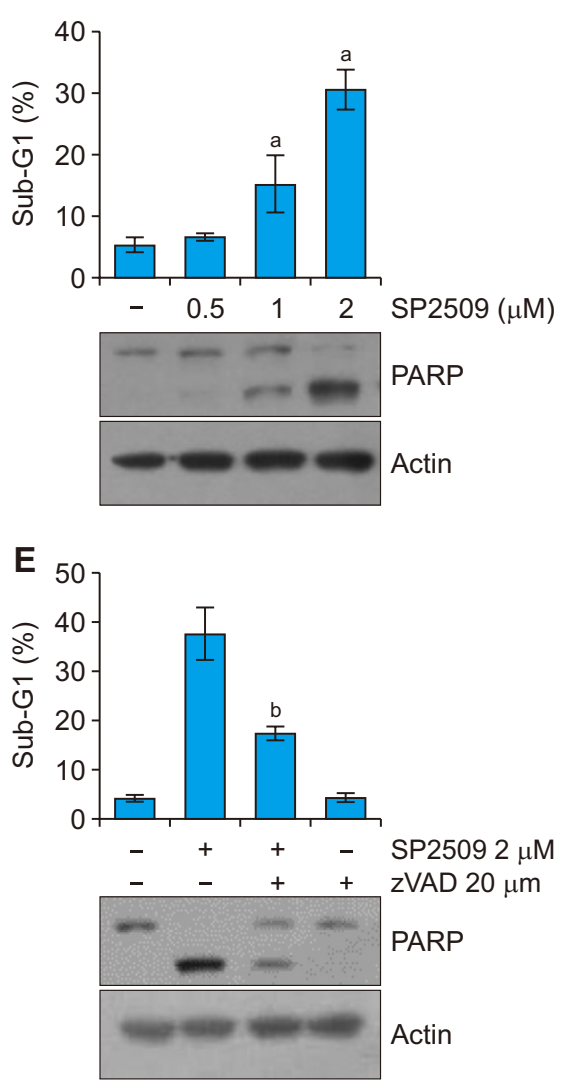

Figure 1. LSD1 inhibitor SP2509 induces apoptosis. (A) Caki cells were treated with SP2509 (0.5-2 $\mu \mathrm{M})$ for 24 hours. The cell morphology and nuclear condensation were examined by using an interference light microscope. White arrows showed nuclear chromatin condensation. (B) The sub-G1 population and protein expression were analyzed by flow cytometry and Western blotting. (C) The fragmentation of the nuclei was determined by using a DNA fragmentation assay kit. (D) Caspase activity was determined by using the caspase DEVDase assay kit. (E) Caki cells were treated with SP2509 $(2 \mu \mathrm{M})$ in the presence or absence of a pan-caspase inhibitor, z-VAD-fmk $(20 \mu \mathrm{M})$ for 24 hours. The sub-G1 population and protein expression were analyzed by flow cytometry and Western blotting. The values in graphs represent the mean \pm SD of three independent samples. DAPI, 4', 6'-diamidino-2-phenylindole. ${ }^{a} P<0.01$ compared to the control. ${ }^{b} P<0.01$ compared to the treatment of SP2509. 
A
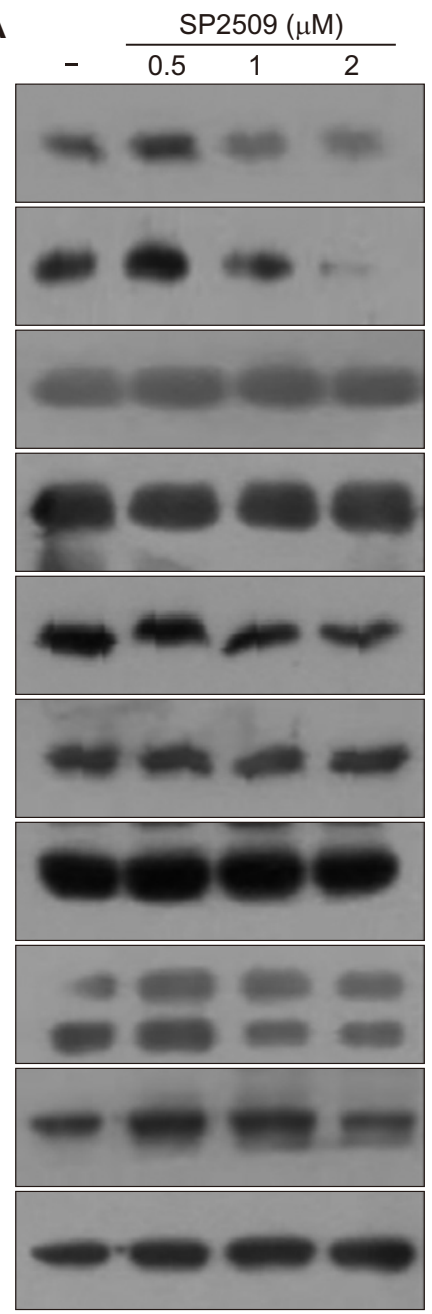

B
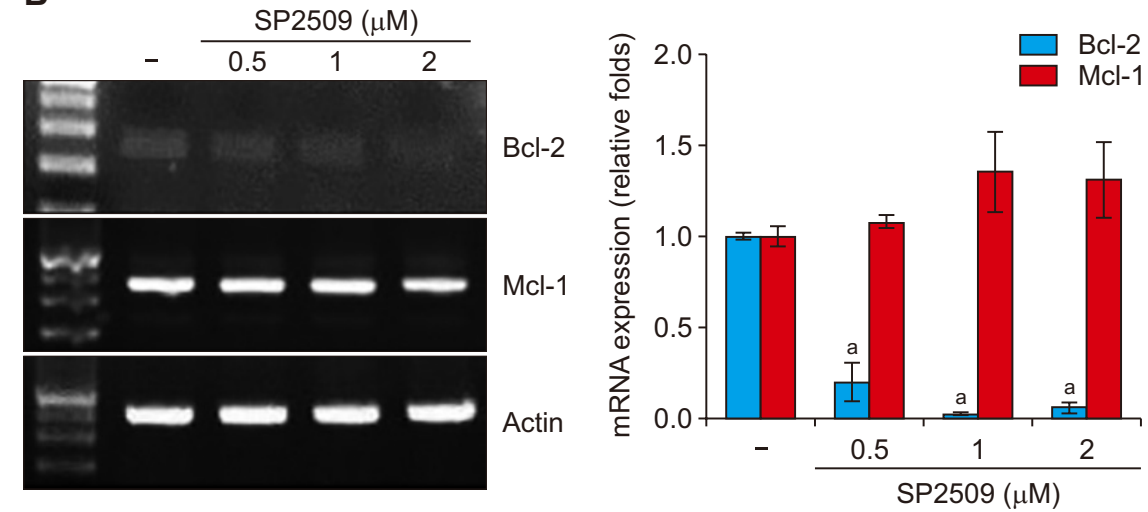

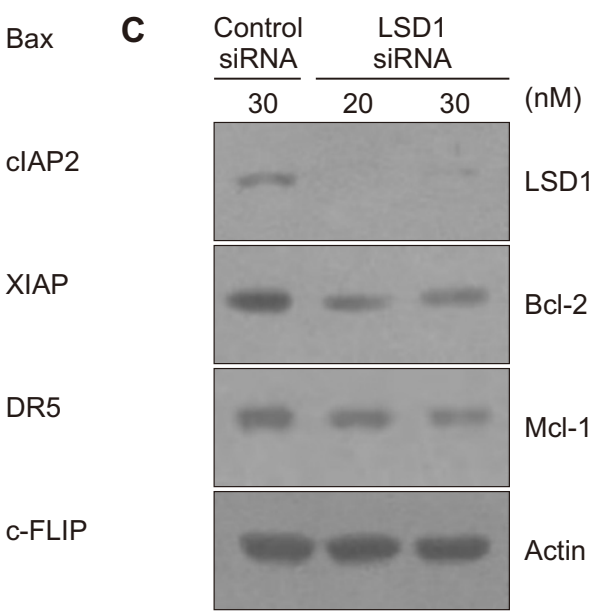

atm

Figure 2. Inhibition of LSD1 induces downregulation of Bcl-2 and Mcl-1 expression. (A) Caki cells were treated with SP2509 (0.5-2 $\mu \mathrm{M})$ for 24 hours. The protein expression levels of anti-apoptotic (Bcl-2, Mcl-1, and Bcl-xL), pro-apoptotic (Bim and Bax) Bcl-2 family, IAP family (clAP2 and XIAP), DR5, c-FLIP, and actin were examined by Western blotting. (B) The mRNA levels of Bcl-2, Mcl-1, and actin were determined by reverse transcription PCR and real-time quantitative PCR. (C) Caki cells were transfected with LSD1 siRNA for 24 hours and the protein levels were measured by Western blotting. The graph represents the mean \pm SD from independent experiments. ${ }^{a} P<0.01$ compared with the control.

A

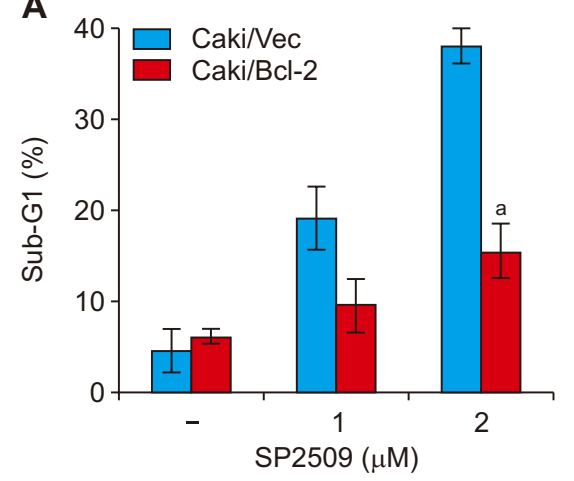

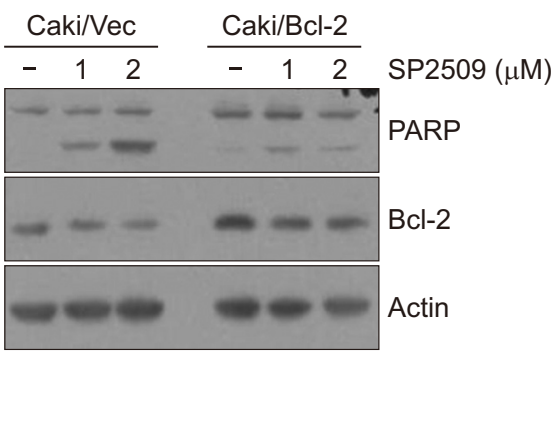

B

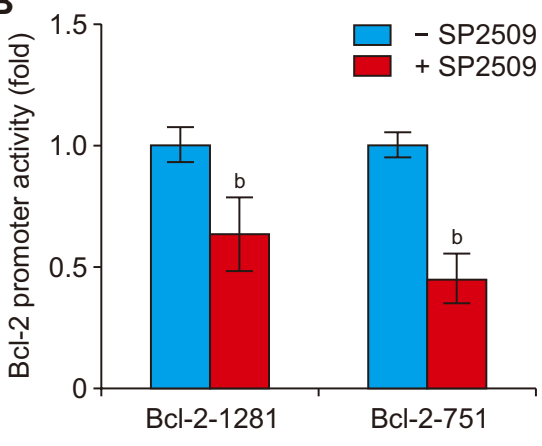

Figure 3. SP2509-induced Bcl-2 downregulation contributes to induction of apoptosis. (A) Vector cells (Caki/Vec) and Bcl-2 overexpressing cells $($ Caki/Bcl-2) were treated with SP2509 $(1-2 \mu \mathrm{M})$ for 24 hours, the protein expression and sub-G1 were examined by Western blotting and flow cytometry. (B) Caki cells were transiently transfected with a plasmid harboring the luciferase under the control of the Bcl-2/-751 and Bcl-2/1281 promoter and then treated with $2 \mu \mathrm{M} \mathrm{SP} 2509$ for 24 hours. The luciferase activity was analyzed. The graphs represent the mean \pm SD from independent experiments. ${ }^{a} P<0.01$ compared with the control in Caki/Vector. ${ }^{b} P<0.01$ compared with the control. 
1 protein expression similar to the effect of LSD1 inhibitor (Fig. 2C). Therefore, these results suggest that inhibition of LSD1 induces downregulation of Bcl-2 and Mcl-1 anti-apoptotic proteins.

\section{SP2509 induces downregulation of Bcl-2 in human renal Caki cells}

To confirm the functional importance of the Bcl-2 reduction in SP2509-induced apoptosis, we analyzed apoptosis using overexpression of Bcl-2 stable cell lines. Ectopic expression of Bcl-2 inhibited SP2509-induced enhancement of sub-G1 population and PARP cleavage (Fig. 3A). We found that Bcl-2 mRNA expression was downregulated by SP2509 treatment (Fig. 2B). Therefore, we investigated the transcriptional regulation of $\mathrm{Bcl}-2$, and found that SP2509 decreased $\mathrm{Bcl}-2$ promoter activity (Fig. 3B). These data indicate that SP2509-induced downregulation Bcl-2 protein is modulated by transcriptional regulation.
A

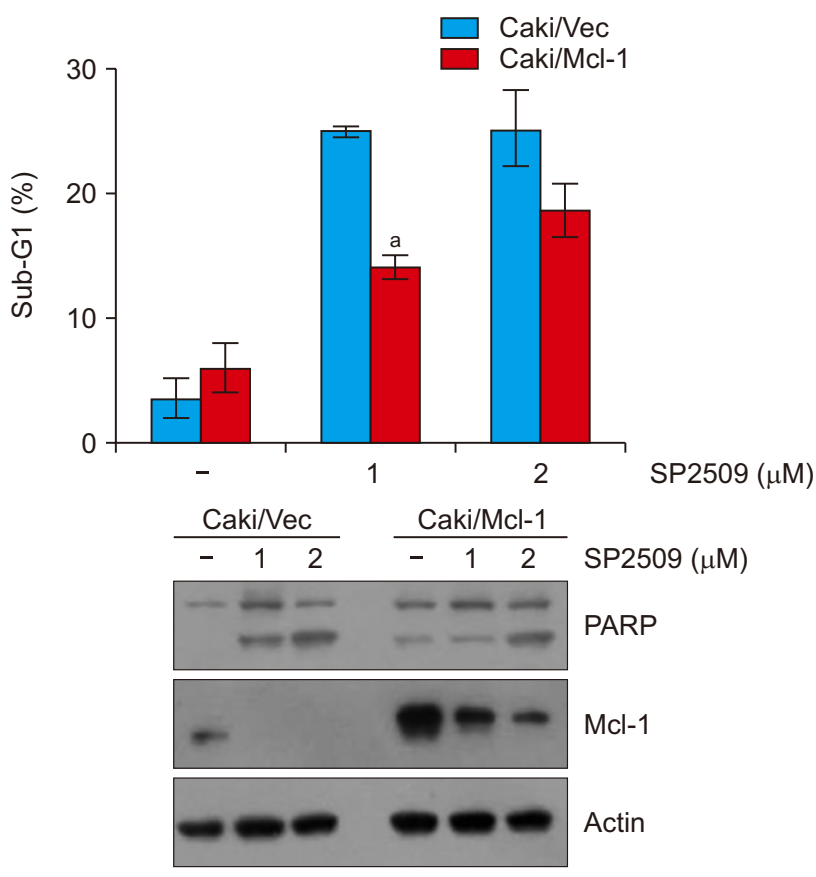

C

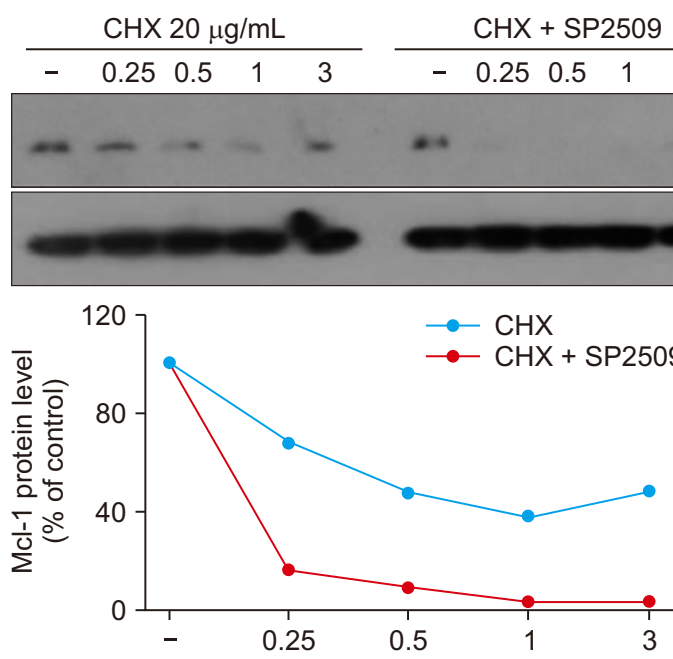

(h)
B
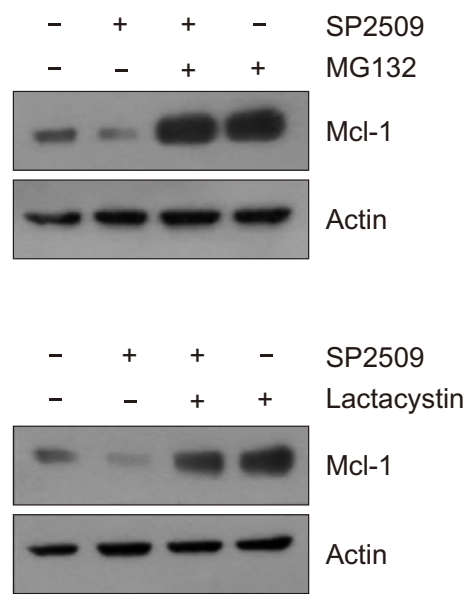

Mcl-1

Actin

D

Mcl-1

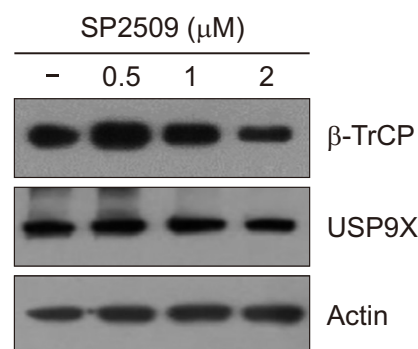

Figure 4. LSD1 inhibitor SP2509 downregulates Mcl-1 expression in Caki cells. (A, B) Vector cells (Caki/Vec) and Mcl-1-overexpressing cells (Caki/Mcl-1) were treated with SP2509 $(2 \mu \mathrm{M})$ for 24 hours. (B) Caki cells were pretreated with MG132 $(1 \mu \mathrm{M})$ and lactacystin $(2.5 \mu \mathrm{M})$ for 30 minutes, then treated with SP2509 $(2 \mu \mathrm{M})$ for 24 hours. (C) Caki cells were treated with or without SP2509 $(2 \mu \mathrm{M})$ in the presence of cycloheximide (CHX) $(20$ $\mu \mathrm{g} / \mathrm{mL}$ ) for the indicated time periods. (D) Caki cells were treated with SP2509 (0.5-2 $\mu \mathrm{M})$. The protein expression levels were examined by Western blotting. (A) The graph represents the mean \pm SD from independent experiments. ${ }^{a} P<0.01$ compared with the SP2509-treated Caki/Vector. 


\section{SP2509 inhibits Mcl-1 protein in human renal Caki cells}

Next, we examined the involvement of Mcl-1 downregulation in SP2509-induced apoptosis. When we treated Mcl-1-overexpressing cells with SP2509, apoptotic population was less than that of vector transfected cells (Fig. 4A). Because SP2509 did not alter Mcl-1 mRNA expression, we explored the degradation of $\mathrm{Mcl}-1$ through post-translational regulation. Two proteasome inhibitors, MG132 and lactacystin, reversed SP2509-induced Mcl-1 downregulation (Fig. 4B). Moreover, when we examined $\mathrm{Mcl}-1$ protein stability using $\mathrm{CHX}$, an inhibitor of protein biosynthesis, CHX plus SP2509 significantly degraded $\mathrm{Mcl}-1$ protein compared to $\mathrm{CHX}$ alone (Fig. 4C). Mcl-1 protein stability is modulated via the ubiquitin-proteasome system. Therefore, we tested the alteration of E3 ligase and deubiquitinase capable of regulating $\mathrm{Mcl}-1$ in
SP2509-treated cells. However, SP2509 did not increase E3 ligase $\beta$-TrCP and decrease USP9X expression (Fig. 4D).

\section{SP2509 selectively induces apoptosis in human renal cancer vs. normal cells}

We next examined the effect of SP2509 on apoptosis in other cancer (renal carcinoma and glioma) and normal cells. SP2509 treatment effectively induced apoptosis and downregulation of $\mathrm{Bcl}-2$ and $\mathrm{Mcl}-1$ expression in renal carcinoma ACHN and U87MG glioma cells (Fig. 5A). In contrast, normal cells (MC and TCMK-1) did not induce morphological change and sub-G1 population by SP2509 (Fig. 5B). Therefore, these data suggest that SP2509 may selectively induce apoptosis in cancer cells.
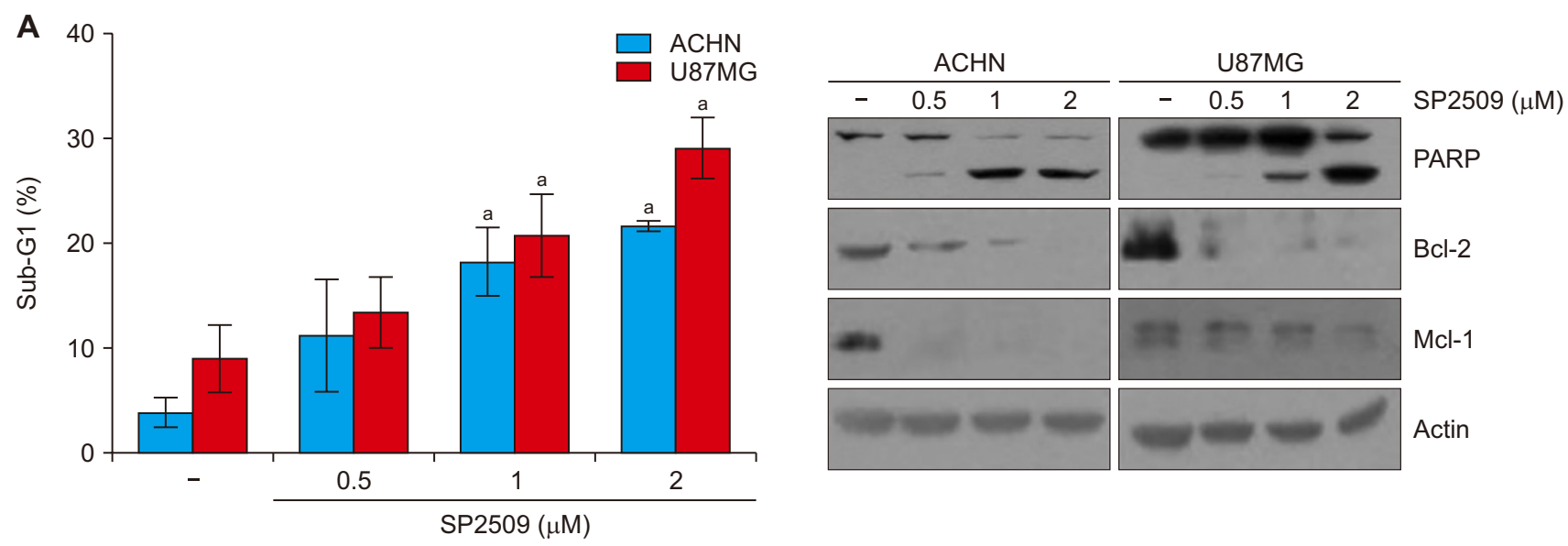

B
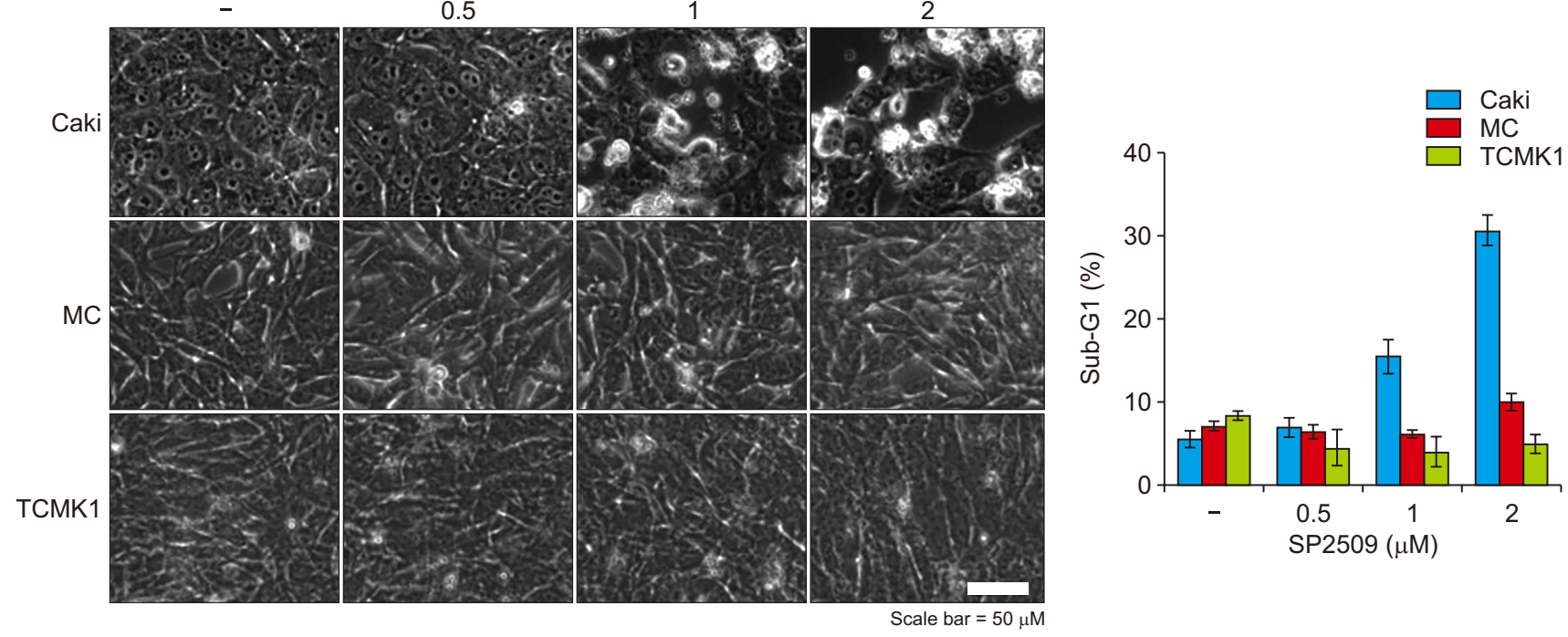

Figure 5. The effect of treatment of SP2509 in various cell lines. (A) Cancer cells (ACHN and U87MG) and normal cells (mesangial cell [MC] and TCMK1) were treated with SP2509 $(0.5-2 \mu \mathrm{M})$ for 24 hours. The sub-G1 cell population was examined by flow cytometry and the protein expression was measured by Western blotting. (B) Cell morphology was determined by interference light microscope. The graphs represent the mean \pm SD from independent experiments. ${ }^{\mathrm{a}} \mathrm{P}<0.01$ compared with control. 


\section{DISCUSSION}

Histone methylation and demethylation imbalances are closely related to tumorigenesis and development [19]. SP2509 is known as a LSD1 inhibitor which exhibits anti-cancer effects. However, anti-cancer effect and molecular mechanisms of SP2509 have not been investigated in renal carcinoma cells. Our results reveal that pharmacological inhibition of LSD1 (SP2509) enhances apoptosis in cancer cells but not in normal cells. SP2509 downregulated Bcl-2 expression at the transcription and $\mathrm{Mcl}-1$ expression at the posttranscriptional levels.

To date, many reversible LSD1 inhibitors have been discovered and their activites were tested in cancer cells. Previously, CBB1007 was found to cell viability in pluripotent and ovarian cancer cells $[20,21]$. In case of 2-PCPA, it induces autophagic flux and cell cycle arrest in human osteosarcoma cells [22]. We first found that knockdown or pharmacologic inhibition of LSD1 downregulates Bcl-2 and Mcl-1 protein expression (Fig. 2A and 2C). SP2509 effectively decreased the protein expression of $\mathrm{Bcl}-2$, and overexpression of $\mathrm{Bcl}-2$ inhibited SP2509-induced cell death (Fig. 2A and 3A). Because SP2509 inhibited Bcl-2 mRNA levels and Bcl-2 promoter activity, suppression of transcription was involved in $\mathrm{Bcl}-2$ downregulation by SP2509 (Fig. 3B). It has been reported that $\mathrm{Bcl}-2$ transcription is regulated by diverse transcription factors, such as p53, NF-кB, c-Myc, and WT1 [23]. p53 is a tumor suppressor and negatively regulates $\mathrm{Bcl}-2$ transcription [24,25]. However, SP2509 did not increase p53 expression (data not shown) in our system, so we rule out the possibility of p53-mediated $\mathrm{Bcl}-2$ regulation. As mentioned above, NF$\kappa \mathrm{B}$ can increase $\mathrm{Bcl}-2$ expression at the transcriptional level, whereas c-Myc decreases Bcl-2 transcription [26,27]. In addition, Wilms' tumor suppressor gene WT1 positively regulates transcriptional level of $\mathrm{Bcl}-2$ by suppressing promoter activity [28]. Therefore, further studies are required to investigate the molecular mechanism responsible for SP2509-mediated Bcl2 suppression.

Our results indicate that SP2509-mediated downregulation of $\mathrm{Mcl}-1$ is associated with the ubiquitin-proteasome pathway. Proteasome inhibitors reversed SP2509-mediated Mcl-1 downregulation (Fig. 4B). Ding et al. [29] demonstrated that E3 ligase $\beta$-TrCP is involved in $\mathrm{Mcl}-1$ degradation, resulting in tumor suppression and sensitization to anti-cancer drugs. Schwickart et al. [30] have also reported that deubiquitinase USP9X stabilizes Mcl-1 expression. Based on these, we checked the alteration of E3 ligase and deubiquitinase capable of regulating Mcl-1 in SP2509-treated cells. However, SP2509 did not change $\beta$-TrCP and USP9X expression (Fig. 4D). Mule/ARF-BP1 and FBXW7 induced Mcl-1 ubiquitination and degradation [31]. In addition, FBXW7 cooperates with $\beta$-TrCP which results in the induction of GSK3 $\beta$-mediated Mcl-1 degradation [32]. Therefore, it'll be of interest to elucidate involvement of these E3 ligases in SP2509-induced degradation of $\mathrm{Mcl}-1$.

Taken together, our results show that downregulation of Bcl-2 and Mcl-1 play a critical role in SP2509-induced apoptosis in renal carcinoma Caki cells, but not in normal cells.

\section{ACKNOWLEDGMENTS}

This work was supported by an NRF grant funded by the Korea Government (MSIP) (2014R1A5A2010008 and NRF2019R1A2C2005921).

\section{CONFLICTS OF INTEREST}

No potential conflicts of interest were disclosed.

\section{ORCID}

Kaixin Wu, https://orcid.org/0000-0003-1409-1399

Seon Min Woo, https://orcid.org/0000-0003-4963-9895

Taeg Kyu Kwon, https://orcid.org/0000-0003-1204-2059

\section{REFERENCES}

1. Greer EL, Shi Y. Histone methylation: a dynamic mark in health, disease and inheritance. Nat Rev Genet 2012;13:343-57.

2. Shi Y, Lan F, Matson C, Mulligan P, Whetstine JR, Cole PA, et al. Histone demethylation mediated by the nuclear amine oxidase homolog LSD1. Cell 2004;119:941-53.

3. D'Oto A, Tian QW, Davidoff AM, Yang J. Histone demethylases and their roles in cancer epigenetics. J Med Oncol Ther 2016;1:34-40.

4. Berry WL, Janknecht R. KDM4/JMJD2 histone demethylases: epigenetic regulators in cancer cells. Cancer Res 2013;73:293642.

5. Majello B, Gorini F, Saccà CD, Amente S. Expanding the role of the histone lysine-specific demethylase LSD1 in cancer. Cancers (Basel) 2019;11:324.

6. Forneris F, Binda C, Vanoni MA, Mattevi A, Battaglioli E. Histone demethylation catalysed by LSD1 is a flavin-dependent oxidative process. FEBS Lett 2005;579:2203-7.

7. Schulte JH, Lim S, Schramm A, Friedrichs N, Koster J, Versteeg $\mathrm{R}$, et al. Lysine-specific demethylase 1 is strongly expressed in poorly differentiated neuroblastoma: implications for therapy. Cancer Res 2009;69:2065-71.

8. Li Y, Deng C, Hu X, Patel B, Fu X, Qiu Y, et al. Dynamic interaction between TAL1 oncoprotein and LSD1 regulates TAL1 function in hematopoiesis and leukemogenesis. Oncogene 2012;31:5007-18.

9. Lv T, Yuan D, Miao X, Lv Y, Zhan P, Shen X, et al. Overexpression of LSD1 promotes proliferation, migration and invasion in non-small cell lung cancer. PLoS One 2012;7:e35065.

10. Jie D, Zhongmin Z, Guoqing L, Sheng L, Yi Z, Jing W, et al. Positive expression of LSD1 and negative expression of E-cadherin correlate with metastasis and poor prognosis of colon 
Wu et al.

cancer. Dig Dis Sci 2013;58:1581-9.

11. Lim S, Janzer A, Becker A, Zimmer A, Schüle R, Buettner R, et al. Lysine-specific demethylase 1 (LSD1) is highly expressed in ER-negative breast cancers and a biomarker predicting aggressive biology. Carcinogenesis 2010;31:512-20.

12. Hayami S, Kelly JD, Cho HS, Yoshimatsu M, Unoki M, Tsunoda $\mathrm{T}$, et al. Overexpression of LSD1 contributes to human carcinogenesis through chromatin regulation in various cancers. Int J Cancer 2011;128:574-86.

13. Wu J, Hu L, Du Y, Kong F, Pan Y. Prognostic role of LSD1 in various cancers: evidence from a meta-analysis. Onco Targets Ther 2015;8:2565-70.

14. Kumar A, Kumari N, Nallabelli N, Sharma U, Rai A, Singh SK, et al. Expression profile of $\mathrm{H} 3 \mathrm{~K} 4$ demethylases with their clinical and pathological correlation in patients with clear cell renal cell carcinoma. Gene 2020;739:144498.

15. McAllister TE, England KS, Hopkinson RJ, Brennan PE, Kawamura A, Schofield CJ. Recent progress in histone demethylase inhibitors. J Med Chem 2016;59:1308-29.

16. Fiskus W, Sharma S, Shah B, Portier BP, Devaraj SG, Liu K, et al. Highly effective combination of LSD1 (KDM1A) antagonist and pan-histone deacetylase inhibitor against human $\mathrm{AML}$ cells. Leukemia 2014;28:2155-64.

17. Seo BR, Min KJ, Cho IJ, Kim SC, Kwon TK. Curcumin significantly enhances dual PI3K/Akt and mTOR inhibitor NVPBEZ235-induced apoptosis in human renal carcinoma Caki cells through down-regulation of p53-dependent Bcl-2 expression and inhibition of Mcl-1 protein stability. PLoS One 2014;9:e95588.

18. Woo SM, Min KJ, Seo BR, Kwon TK. YM155 sensitizes TRAILinduced apoptosis through cathepsin S-dependent downregulation of $\mathrm{Mcl}-1$ and $\mathrm{NF}-\kappa \mathrm{B}-$ mediated down-regulation of c-FLIP expression in human renal carcinoma Caki cells. Oncotarget 2016;7:61520-32.

19. Kondo Y. Epigenetic cross-talk between DNA methylation and histone modifications in human cancers. Yonsei Med J 2009;50:455-63.

20. Wang J, Lu F, Ren Q, Sun H, Xu Z, Lan R, et al. Novel histone demethylase LSD1 inhibitors selectively target cancer cells with pluripotent stem cell properties. Cancer Res 2011;71:7238-49.

21. Konovalov S, Garcia-Bassets I. Analysis of the levels of lysine- specific demethylase 1 (LSD1) mRNA in human ovarian tumors and the effects of chemical LSD1 inhibitors in ovarian cancer cell lines. J Ovarian Res 2013;6:75.

22. Wang Z, Long QY, Chen L, Fan JD, Wang ZN, Li LY, et al. Inhibition of $\mathrm{H} 3 \mathrm{~K} 4$ demethylation induces autophagy in cancer cell lines. Biochim Biophys Acta Mol Cell Res 2017;1864:242837.

23. Siddiqui WA, Ahad A, Ahsan $\mathrm{H}$. The mystery of BCL2 family: Bcl2 proteins and apoptosis: an update. Arch Toxicol 2015;89:289317.

24. Miyashita T, Krajewski S, Krajewska M, Wang HG, Lin HK, Liebermann DA, et al. Tumor suppressor p53 is a regulator of bcl-2 and bax gene expression in vitro and in vivo. Oncogene 1994;9:1799-805.

25. Mihara M, Erster S, Zaika A, Petrenko O, Chittenden T, Pancoska P, et al. p53 has a direct apoptogenic role at the mitochondria. Mol Cell 2003;11:577-90.

26. Heckman CA, Mehew JW, Boxer LM. NF-kappaB activates Bcl-2 expression in $\mathrm{t}(14 ; 18)$ lymphoma cells. Oncogene 2002;21:3898908.

27. Eischen CM, Woo D, Roussel MF, Cleveland JL. Apoptosis triggered by Myc-induced suppression of $\mathrm{Bcl}-\mathrm{X}(\mathrm{L})$ or $\mathrm{Bcl}-2$ is bypassed during lymphomagenesis. Mol Cell Biol 2001;21:506370.

28. Loeb DM. WT1 influences apoptosis through transcriptional regulation of Bcl-2 family members. Cell Cycle 2006;5:1249-53.

29. Ding Q, He X, Hsu JM, Xia W, Chen CT, Li LY, et al. Degradation of $\mathrm{Mcl}-1$ by beta-TrCP mediates glycogen synthase kinase 3 -induced tumor suppression and chemosensitization. Mol Cell Biol 2007;27:4006-17.

30. Schwickart M, Huang X, Lill JR, Liu J, Ferrando R, French DM, et al. Deubiquitinase USP9X stabilizes MCL1 and promotes tumour cell survival. Nature 2010;463:103-7.

31. Zhong Q, Gao W, Du F, Wang X. Mule/ARF-BP1, a BH3-only E3 ubiquitin ligase, catalyzes the polyubiquitination of $\mathrm{Mcl}-1$ and regulates apoptosis. Cell 2005;121:1085-95.

32. Ren H, Koo J, Guan B, Yue P, Deng X, Chen M, et al. The E3 ubiquitin ligases $\beta$-TrCP and FBXW7 cooperatively mediates GSK3-dependent Mcl-1 degradation induced by the Akt inhibitor API-1, resulting in apoptosis. Mol Cancer 2013;12:146. 